Original scientific paper

\title{
NUMERICAL MODEL FOR WORM GEAR PAIR INSPECTION BASED ON 3D SCANNED DATA
}

\author{
Masovic, R.; Breski, T.; Cular, I.; Vuckovic, K. \& Zezelj, D. \\ University of Zagreb, Faculty of Mechanical Engineering and Naval Architecture, I. Lučića 5, \\ 10000 Zagreb, Croatia \\ E-Mail: robert.masovic@fsb.hr
}

\begin{abstract}
Gear inspection is an important aspect for evaluating gear geometry and ensuring that specified dimensional requirements are met. It is commonly carried out via tactile measurement methods which are characterized by relatively slow data acquisition and inability to provide three-dimensional data of the entire inspected object. In this paper, an alternative method based on three-dimensional optical scanning is employed for the inspection of a worm gear pair. Apart from assessing most common errors such as pitch deviations and runout, a nonlinear quasi-static finite element analysis based on worm gear pair scan is developed to estimate the transmission error. Furthermore, transmission error and initial worm wheel contact pattern are evaluated under running-in load and various assembly errors which resemble realistic working conditions. Depending upon the specific assembly error, transmission error can be either increased or decreased. Variation of initial contact patterns between observed worm wheel tooth flanks can vary up to $50 \%$. The results suggest that geometrical deviations have a considerable impact on initial contact patterns.

(Received in June 2021, accepted in September 2021. This paper was with the authors 2 weeks for 1 revision.)
\end{abstract}

Key Words: Gear Inspection, Worm Gear Pair, Worm Wheel, Transmission Error, 3D Optical Scan, Contact Pattern

\section{INTRODUCTION}

Worm gear pairs are used for power and motion transmission where a high transmission ratio in a single gear stage is required. Hence, they are characterized by smaller assembly sizes when compared to other gear types. Most often, a worm is a driving and a worm wheel is a driven part of a worm gear pair. Due to their geometry, worm gears are sensitive to manufacturing and assembly errors. Simon [1] observed that a relatively small tooth spacing error of $15 \mu \mathrm{m}$ can increase contact stresses by $50 \%$. Falah et al. [2] investigated the load distribution of worm wheels. The authors concluded that assembly errors can increase contact stresses. To reduce the sensitivity of worm gears to assembly and manufacturing errors, the worm wheel is usually manufactured with an oversized hob, which also applies to the inspected worm wheel in this paper. Geometrical and operating parameters of the hob have a direct impact on tooth contact. More specifically, line contact is transformed into a point contact. Furthermore, the contact is often positioned on the leaving side of the tooth to ensure adequate oil supply within the contact zone. However, adverse effects of such manufacturing methods are manifested in the form of contact stress and transmission error increase, as well as the occurrence of edge contact $[3,4]$.

Dimensional gear inspection is typically carried out by employing coordinate measuring machines (CMMs) or gear measuring instruments (GMIs) [5]. Moreover, to determine the transmission error, gears are tested on specialized rigs where a single flank rolling test (tangential composite gear inspection) is performed [6]. Transmission error is defined as the deviation of the position of the driven gear, for a given angular position of the driving gear, from the position that the driven gear would occupy if the gears were geometrically perfect [7]. During a single flank rolling test, mating gears are rolled together with backlash at a specified centre distance with only one flank in contact. In this manner, gear operation is simulated more accurately than any other method of gear evaluation. Single flank rolling test results can also 
reveal individual inaccuracies such as pitch and runout errors [8]. Moreover, transmission error has harmful effects on the gear pair. It can induce shocks, vibrations, and consequently reduce the load capacity of the gear [9]. Opalić et al. [10] observed that the transmission error due to manufacturing faults could be one of the explanations for uneven pitting distribution on worm wheel teeth flanks.

In recent years, with the advancement of measuring methods and techniques, fast accurate measuring of complex geometry (such as gear geometry) became a possibility. While commonly employed gear measuring systems (e.g. CMMs and GMIs) provide accurate measurement with low measurement uncertainty, their data acquisition is time-consuming and they are unable to provide three-dimensional (3D) data of the entire geometry. Moreover, multiple measuring systems or test rigs are often required to fully inspect a gear pair according to relevant standards $[11,12]$. As an alternative, several non-contact measurement methods capable of fast data acquisition resulting in 3D spatial scan of complex geometry can be employed in gear inspection, such as computed tomography (CT), optical 3D scanning [13], and other optical methods such as the Moire method [14]. Amongst mentioned methods, 3D optical scanning provides a high sampling rate, the ability to scan objects made from any material accompanied with high measurement accuracy, and it is relatively simple to use. The main disadvantage of 3D optical scanning is the lack of universally accepted standard for the performance evaluation of such systems. This, in turn, limits their applications in strictly regulated industries and when measuring small objects with fine tolerances. Currently, VDI/VDE 2634 [15] is the only general guideline employed for verification of scanner accuracy. Recent studies are directed towards the estimation of measurement uncertainty and accuracy in 3D optical scanning. Urbas et al. [16] obtained combined measurement uncertainty of $4.24 \mu \mathrm{m}$ when scanning polymer gears. Ghandali et al. [17] determined expanded uncertainty for structured-light 3D scanners based on novel reference artifacts. Estimated expanded uncertainties were $4.42 \mu \mathrm{m}$ for distance and $1.28 \mu \mathrm{m}$ for size and form. The capability of a 3D optical scanner is dependent on measuring volume, object size, and tolerance being evaluated. Although 3D optical scanners are not suitable for measuring small objects which require high precision, they are suitable for medium to large size objects with lenient tolerances [18].

Currently, many investigations based on the analytical formulation of worm gears have been conducted to determine the effects of assembly and manufacturing errors on load distribution, contact stresses, and transmission error $[1,2,19,20]$. Finite element (FE) analysis is often employed in simulating gear transmission $[21,22]$. Numerical models based on the FE method were established to investigate new and modified worm gear pair geometry [23, 24]. However, the existing research is based on either geometrically ideal worm gear pair models or artificially introduced individual geometrical errors. Manufactured worm pair has geometrical errors which are stochastically distributed and whose joint effect cannot be easily modelled or predicted. In this paper, a 3D optically scanned model of worm pair is imported in FE software where analyses under no-load and running-in load conditions are conducted. The presented method enables estimation of the transmission error and initial contact pattern of asmanufactured worm gear pair. In addition, worm gear pair is dimensionally inspected according to DIN 3974 [11, 12]. Employing 3D scans in dimensional inspection and FE analysis enables defining all worm gear pair deviations specified by standards. Consequently, the employment of inspecting machines and testing rigs in worm gear pair inspection can be minimized.

\section{METHODS}

\subsection{D optical scanning process}

To obtain spatial models and conduct measurements, the worm pair is 3D optically scanned along with the corresponding housing. The worm and worm wheel are scanned within the 
measuring volume of the scanner equal to $200 \mathrm{~mm} \times 150 \mathrm{~mm} \times 150 \mathrm{~mm}$. Referent worm pair data is given in Table I. Due to its size, the housing is scanned by employing a scanner with a larger measuring volume of $320 \mathrm{~mm} \times 240 \mathrm{~mm} \times 240 \mathrm{~mm}$. The acceptance test values, which are used to verify the accuracy of the scanners, are provided in Table II. Most features of scanned objects are not visible from a single measurement position. Therefore, reference points must be placed on the object to enable the scanner (camera) to accurately position during multiple scans. Scanned objects must be opaque as reflection affects the quality of the results. Since the test gears are not completely opaque, a layer of titanium oxide alcohol solution must be applied to reduce reflection. During the scanning process, fringe patterns are projected onto the surface of the scanned object while the object is incrementally rotated. The scanning process results in several partial scans which are then merged into a single point cloud representing the scanned geometry using ATOS Professional software package [25].

Table I: Worm pair employed in this paper.

\begin{tabular}{|l|c|}
\hline Number of teeth (wheel) & 36 \\
\hline Number of teeth (worm) & 2 \\
\hline Module $(\mathrm{mm})$ & 4 \\
\hline Reference circle diameter $(\mathrm{mm})$ & 144 \\
\hline Profile shift coefficient $(\mathrm{mm})$ & 0 \\
\hline Pressure angle $\left(^{\circ}\right)$ & 20 \\
\hline Centre distance $(\mathrm{mm})$ & 90 \\
\hline Helix & Right-hand \\
\hline Flank type & ZN \\
\hline
\end{tabular}

Table II: Acceptance test values.

\begin{tabular}{|c|c|c|c|}
\hline Scanner & $\begin{array}{c}\text { Atos Core 200 } \\
(M V: 200 \mathrm{~mm} \times 150 \mathrm{~mm} \\
\times 150 \mathrm{~mm})\end{array}$ & $\begin{array}{c}\text { Atos III } \\
(M V: 320 \mathrm{~mm} \times 240 \mathrm{~mm} \\
\times 240 \mathrm{~mm})\end{array}$ & \\
\hline Parameter & $\begin{array}{c}\text { Maximum deviation } \\
(\mathrm{mm})\end{array}$ & $\begin{array}{c}\text { Maximum deviation } \\
(\mathrm{mm})\end{array}$ & $\begin{array}{l}\text { Limit } \\
(\mathrm{mm})\end{array}$ \\
\hline Probing error form (sigma) & 0.002 & 0.001 & 0.004 \\
\hline Probing error (size) & -0.006 & 0.004 & 0.015 \\
\hline Sphere spacing error & 0.010 & 0.006 & 0.012 \\
\hline Length measurement error & 0.016 & -0.006 & 0.027 \\
\hline
\end{tabular}

\subsection{Processing of scanned data}

To obtain worm pair and housing deviations, scanned data is processed and analysed in GOM Inspect software [26]. Worm pair is inspected according to DIN 3974 standard [11, 12]. The inspection scope consists of pitch deviations (single pitch deviation $f_{\mathrm{p}}$, adjacent pitch difference $f_{\mathrm{u}}$, and total cumulative pitch deviation $F_{\mathrm{p}}$ ), total profile deviation $F_{\alpha}$, runout $F_{\mathrm{r}}$, and transmission error (tooth-to-tooth error $f_{\mathrm{i}}$ ' and total transmission error $F_{\mathrm{i}}$ '). The housing is inspected in terms of centre distance and shaft angle error (see Fig. 1). These errors are referred to as assembly errors in "Results and discussion" section of this paper. 


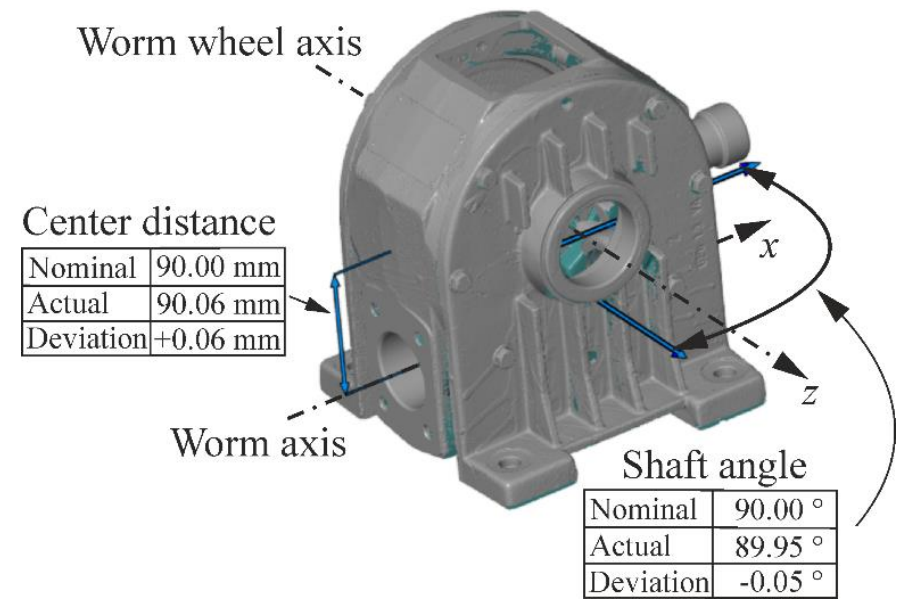

Figure 1: Housing deviations.

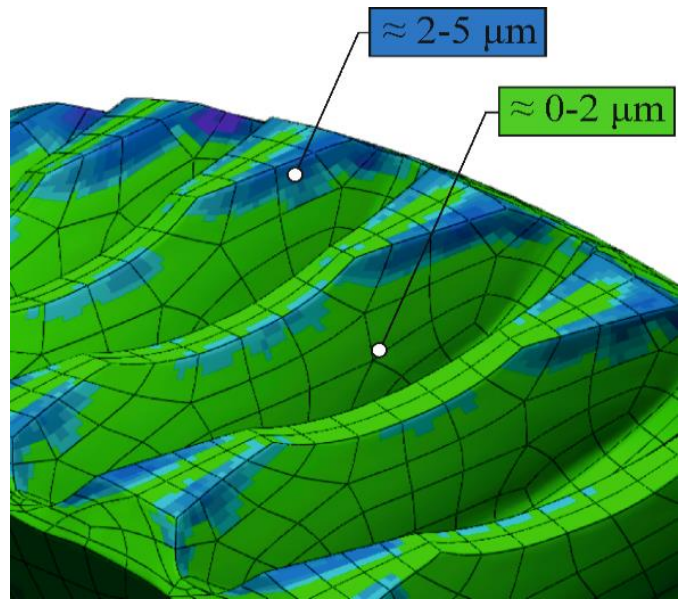

Figure 2: Surface fitting error.

\subsection{Transmission error}

As previously defined, transmission error is the deviation of the position of the driven gear (for a given angular position of the driving gear) from the position that the driven gear would occupy if the gears were geometrically perfect [7],

$$
T E=\varphi_{2} r_{2}-\varphi_{1} \frac{z_{1}}{z_{2}} r_{2}
$$

where $\varphi_{2}$ is the angular position of the driven gear, $\varphi_{1}$ is the angular position of the driving gear, $r_{2}$ is the reference circle radius of the driven gear, and $z_{1}$ and $z_{2}$ are the number of teeth of driving and driven gear, respectively. Under no-load measurement against a master gear with error-free assembly conditions, deviations are denoted as tooth-to-tooth error $f_{\mathrm{i}}$ ' and no-load total transmission error $F_{\mathrm{i}}$ '. To avoid confusion, if the tangential composite inspection is carried out on a complete gear set under operating conditions, deviations are denoted as $w_{\mathrm{i}}$ ' and $W_{\mathrm{i}}$ ' [27]. With the purpose of investigating transmission error behaviour of as-manufactured worm pair in real application, the operating conditions are simulated with the inclusion of running-in load and assembly errors. Usually, during the running-in phase of the worm pair, the load is gradually applied in steps until a desirable contact pattern on worm wheel teeth flanks is achieved. The investigated worm pair is designed for constant $200 \mathrm{Nm}$ nominal load application. During the running-in phase, as a first load step, $40 \%$ of the nominal load is employed. In other words, $80 \mathrm{Nm}$ torque is applied for the transmission error inspection under running-in conditions. The transmission error is evaluated by FE analysis which is explained in detail in the following section.

\subsection{Finite element model}

Before numerical analysis can be conducted via finite element (FE) software, GOM Inspect [26] is employed to trim redundant components of the scanned gear pair such as worm wheel central hub and bolts. Since GOM Inspect provides STL format as the output, it has to be converted into a format that enables mesh editing. Therefore, Geo Magic software [28] is employed to convert the STL format to SAT format. Thus, a surface model is created which is then input into Abaqus [29], a software for FE analysis. Deviations of the surface model from the underlying mesh are shown in Fig. 2. It should be noted that the STL format can also be directly opened in Abaqus. However, the resulting mesh would be characterized as an orphan mesh [29] which cannot be optimized for computational efficiency. The result of the aforementioned procedure is a closed surface model representing the geometry of the scanned 
gears. The above-described process, which is illustrated on the worm wheel example in Fig. 3, is repeated for both the worm wheel and the worm.

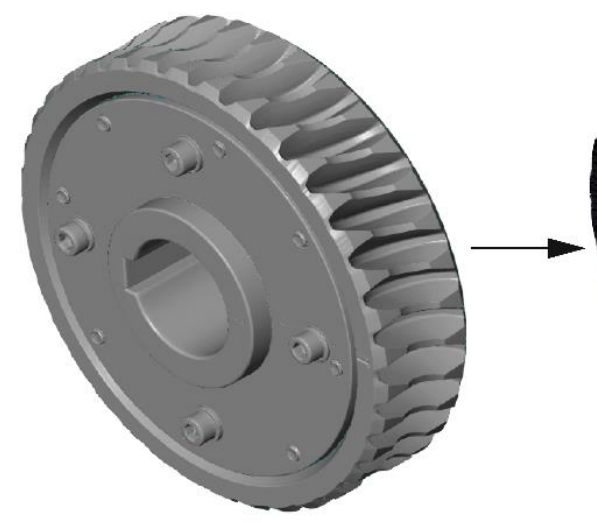

scan model

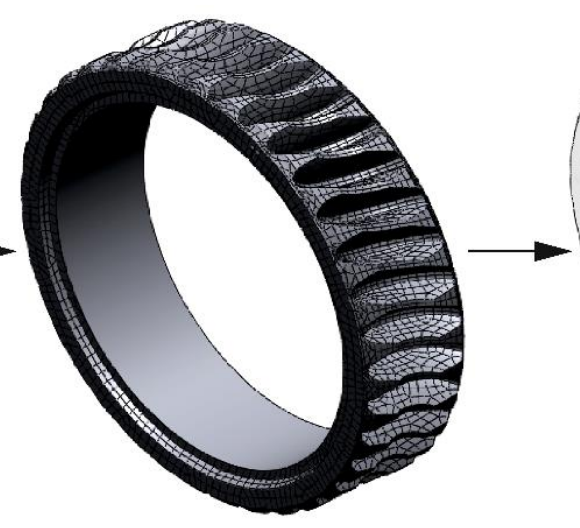

surface model

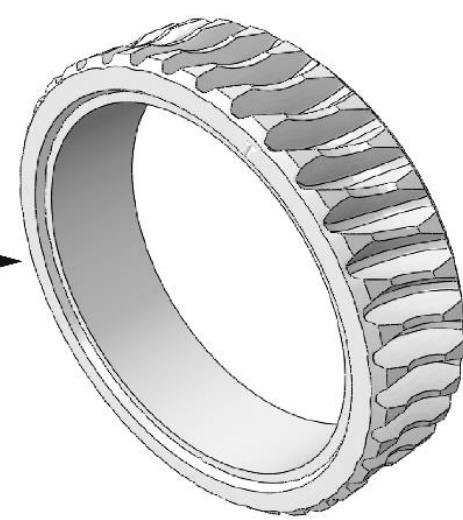

imported part

Figure 3: Establishing the worm wheel part.

The worm is made of carburized steel designated as $16 \mathrm{MnCr} 5$ (Young's modulus $E=210$ $\mathrm{GPa}$; Poisson's ratio $v=0.3$ ), while the worm wheel is made of AlSn6 alloy (Young's modulus $E=100 \mathrm{GPa}$, Poisson's ratio $v=0.33$ ). The material is assumed as homogeneous, isotropic, and linear-elastic. A quasi-static analysis is carried out in Abaqus Standard solver. Boundary conditions and contact properties are based on the existing FE model established in [23], where contact between teeth flanks for a static loading case was modelled. However, the FE model proposed in this paper also accounts for the rotation of the worm pair. As such, it enables representation of actual worm pair contact patterns. The boundary conditions are shown in Fig. 4.

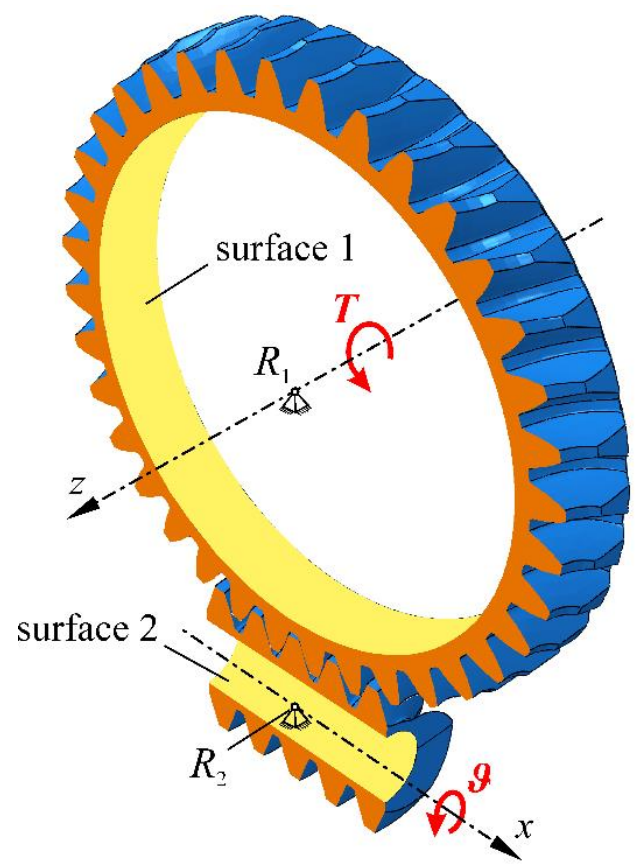

a)

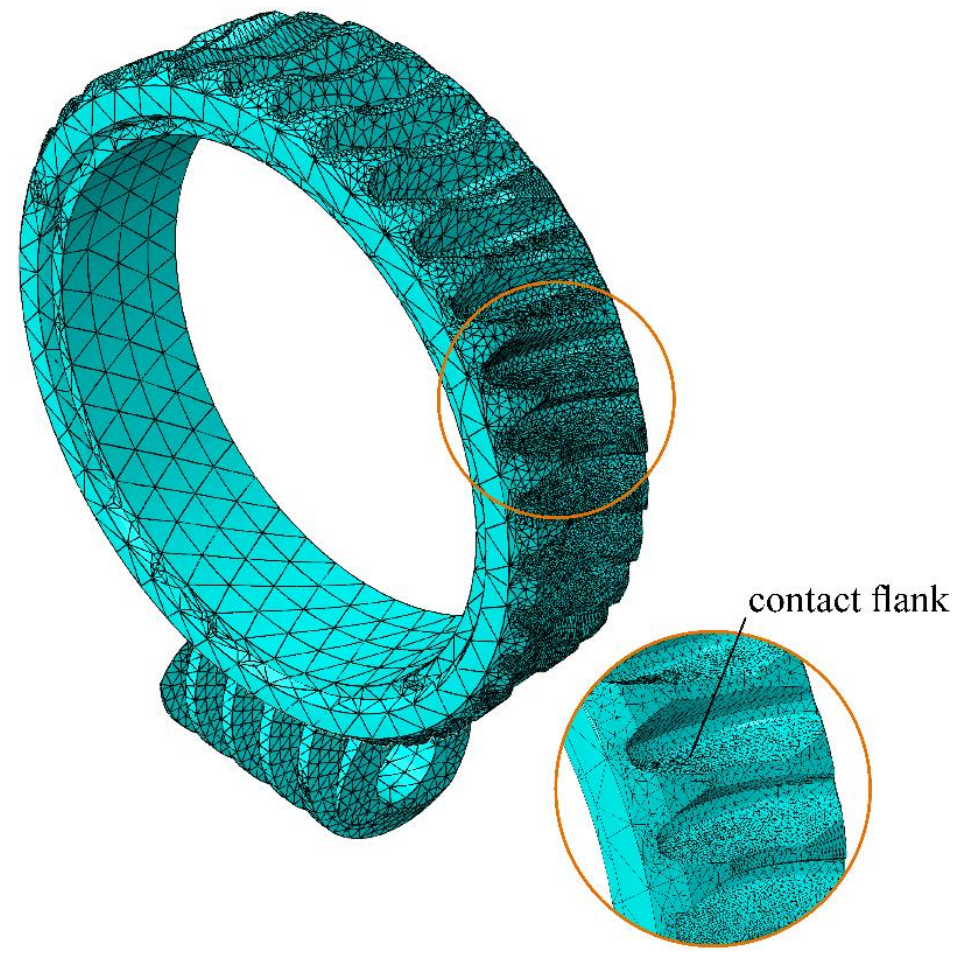

c)

Figure 4: FE model of worm gear pair: a) boundary conditions (section view), b) mesh, and c) contact flank mesh (detail). 
The boundary conditions are set as follows:

- Inner worm wheel surface 1 is coupled to a reference point $\mathrm{R}_{1}$ with all degrees of freedom restrained. The reference point is placed at the origin of the worm wheel coordinate system. Only rotation about the $\mathrm{z}$-axis of the worm wheel is enabled at node $\mathrm{R}_{1}$.

- Inner worm surface 2 is coupled to a reference point $\mathrm{R}_{2}$ with all degrees of freedom restrained. Reference point $\mathrm{R}_{2}$ is placed at the origin of the worm coordinate system. Only rotation about the $\mathrm{x}$-axis of the worm is enabled at node $\mathrm{R}_{2}$.

- A negligible torque value of $T=1 \mathrm{Nm}$ is assigned to the reference point $\mathrm{R}_{1}$ in no-load transmission error analysis to satisfy boundary conditions and achieve analysis convergence. For two-threaded worm, a rotation angle of $\vartheta \approx 113.1 \mathrm{rad}$ is chosen as an input parameter to achieve one full rotation of the worm wheel $\left(360^{\circ}\right)$.

- Four contact surface sets are created. Tooth surfaces on the worm (two-threaded worm) correspond to two surface sets. Worm wheel tooth flanks are divided into two sets, with each set containing 18 tooth flank surfaces. A general contact algorithm with a master-slave surface definition is used. Worm surfaces are set as master surfaces (commonly applied to harder material), while worm wheel tooth flanks are selected as slave surfaces. A penalty method with "hard" contact formulation is employed. Friction is included by the penalty method with constant friction coefficient set to 0.06 [30].

Elements C3D10 (tetrahedral, second-order elements [29]) are employed due to the presence of curved and complex surfaces. The analysis is divided into three steps. In the initial step, boundary conditions are assigned. In the second step, contact between the worm wheel and the worm is achieved. Lastly, in the third step, rotation of the worm wheel is established. To ensure adequate resolution of the gear meshing, the third step is separated into 3600 frames evenly distributed through complete rotation of the worm wheel, thus providing 100 frames per pitch. Since each frame represents a static loading case, a quasi-static simulation is established. Non-linear geometry is employed to account for the effect of large displacements. Mesh refinement is applied on contacting surface until the analysis results converged. The approximate mesh size of $1.5 \mathrm{~mm}$ on the worm and $1 \mathrm{~mm}$ on the worm wheel contact surfaces are adopted for all FE analyses conducted in this paper.

\section{RESULTS AND DISCUSSION}

\subsection{Worm pair and housing deviations}

Dimensional inspection results of the scanned worm pair carried out by employing GOM Inspect software are presented in Table III. Transmission errors are determined through FE analysis of the inspected worm pair by outputting rotational displacements at reference nodes $\mathrm{R}_{1}$ and $\mathrm{R}_{2}$. The scanned (as-manufactured) worm is meshed with the referent (ideal) CAD model of the worm wheel, while the scanned (as-manufactured) worm wheel is meshed with the referent (ideal) CAD model of the worm. Referent CAD models are generated through KISSsoft AG software [31]. Results of worm wheel runout and total cumulative pitch error are presented in Figs. 6 and 7 where horizontal axes denote the location of the worm wheel tooth space and flank, thus amounting to a total of 36 instances numbered from No. 1 to No. 36. The transmission error obtained for two rotations of the as-manufactured worm is presented in Fig. 5. For each $\pi$ radian rotation, the transmission error of a single worm thread can be evaluated. Based on the results, a second thread of the worm has a larger tooth-to-tooth error, which also corresponds to worm total transmission error $F_{\mathrm{i}}$ '. Worm wheel tooth-to-tooth and total transmission error are evaluated as $47.9 \mu \mathrm{m}$ and $74 \mu \mathrm{m}$, respectively. 
Table III: Worm gear pair deviations.

\begin{tabular}{|l|c|c|c|c|}
\hline \multicolumn{1}{|c|}{ Deviation } & $\begin{array}{c}\text { Worm } \\
(\mu \mathrm{m})\end{array}$ & $\begin{array}{c}\text { Quality } \\
\text { grade }\end{array}$ & $\begin{array}{c}\text { Worm wheel } \\
(\mu \mathrm{m})\end{array}$ & $\begin{array}{c}\text { Quality } \\
\text { grade }\end{array}$ \\
\hline Single pitch deviation $f_{\mathrm{p}}$ & 13.9 & 8 & 34.9 & 10 \\
\hline Adjacent pitch difference $f_{\mathrm{u}}$ & 7.3 & 5 & 66.1 & 11 \\
\hline Total cumulative pitch deviation $F_{\mathrm{p} 2}$ & - & - & 34.9 & 6 \\
\hline Lead total deviation $F_{\mathrm{pz}}$ & 21.7 & 8 & - & - \\
\hline Total profile deviation $F_{\alpha}$ & 107 & 12 & 141 & 12 \\
\hline Runout $F_{\mathrm{r}}$ & 52 & 10 & 101.5 & 11 \\
\hline Tooth-to-tooth error $f_{\mathrm{i}}{ }^{\prime}$ & 49.3 & 10 & 47.9 & 10 \\
\hline Total transmission error $F_{\mathrm{i}}{ }^{\prime}$ & 49.3 & 8 & 74 & 8 \\
\hline
\end{tabular}

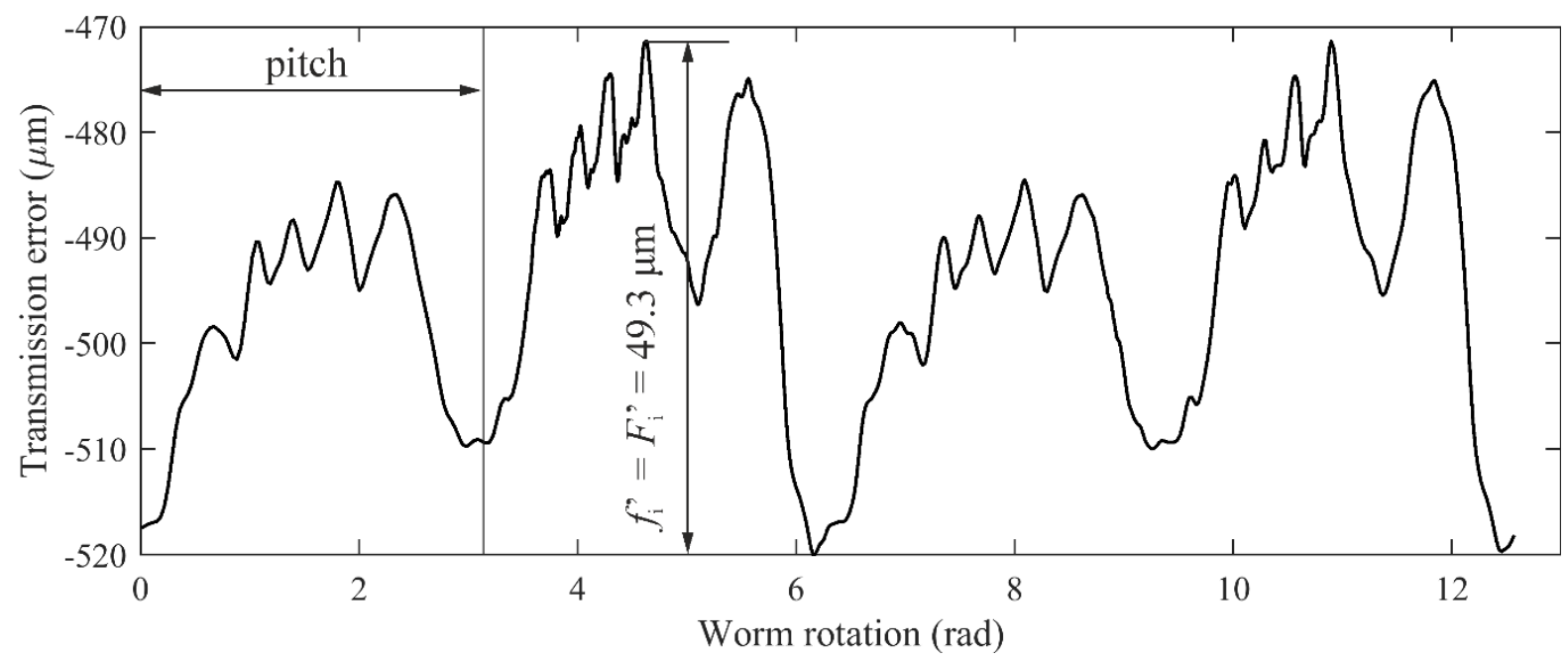

Figure 5: Transmission error - worm.

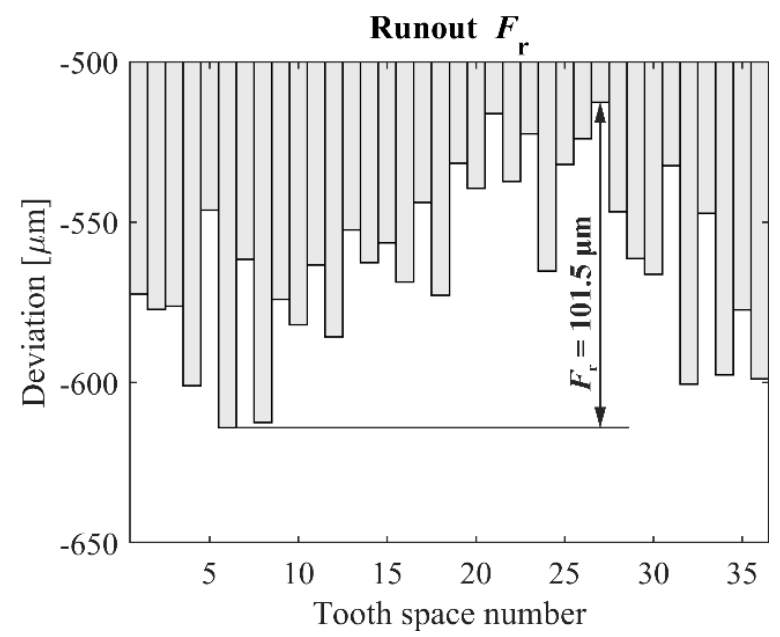

Figure 6: Worm wheel runout $F_{\mathrm{r}}$.

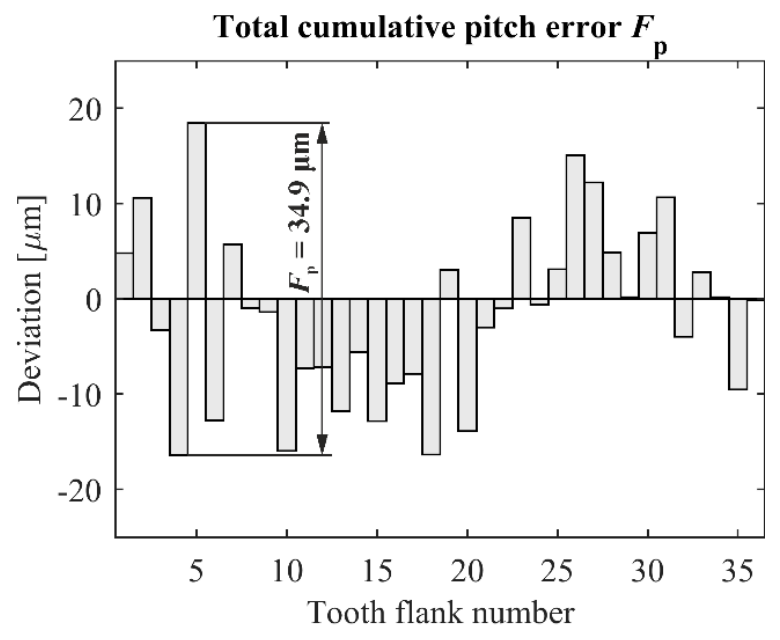

Figure 7: Worm wheel total cumulative pitch error $F_{\mathrm{p}}$.

\subsection{Transmission error and initial contact pattern under operating conditions}

Transmission error and initial contact pattern under operating conditions are evaluated under the running-in load of $80 \mathrm{Nm}$ accompanied with various assembly error cases. Assembly errors included in the FE model are defined as the housing centre distance and shaft angle errors as shown in Fig. 1. According to [26], tooth-to-tooth error under operating conditions is denoted $w_{\mathrm{i}}$,' whereas total transmission error is denoted $W_{\mathrm{i}}$ '. 
Worm wheel tooth-to-tooth error $w_{\mathrm{i}}$ ' and total transmission error $W_{\mathrm{i}}$ ' without assembly errors amount to $39.1 \mu \mathrm{m}$ and $64.8 \mu \mathrm{m}$, respectively. To further investigate the effect of individual assembly errors on the transmission error of the inspected worm pair, FE analyses with various assembly error cases are conducted (see Figs. 9, 10, and 11). It can be observed that transmission error has a waveform, which indicates the presence of the runout in the worm wheel [8]. During the manufacturing process, the worm wheel is usually manufactured to ensure contact on the leaving side of the worm wheel tooth flank (see Fig. 8). Leaving side contact is favourable because it enables oil supply to the contact zone, thus providing adequate lubricating conditions [32]. For the inspected worm pair, shaft angle error has a more significant effect on transmission error results when compared to the effect of the centre distance error. As the contact zone is established on the leaving side, negative shaft angle error drives the contact even more to the edge of the flank, thus creating potential leaving edge contacts (see Fig. 8, blue contact pattern). Combined assembly errors (centre distance error of $+0.06 \mathrm{~mm}$ and shaft angle error of $-0.05^{\circ}$ ), expected in operation based on the worm pair housing scan, result in the highest increase in the transmission error for the inspected worm pair. The results summary is presented in Table IV.

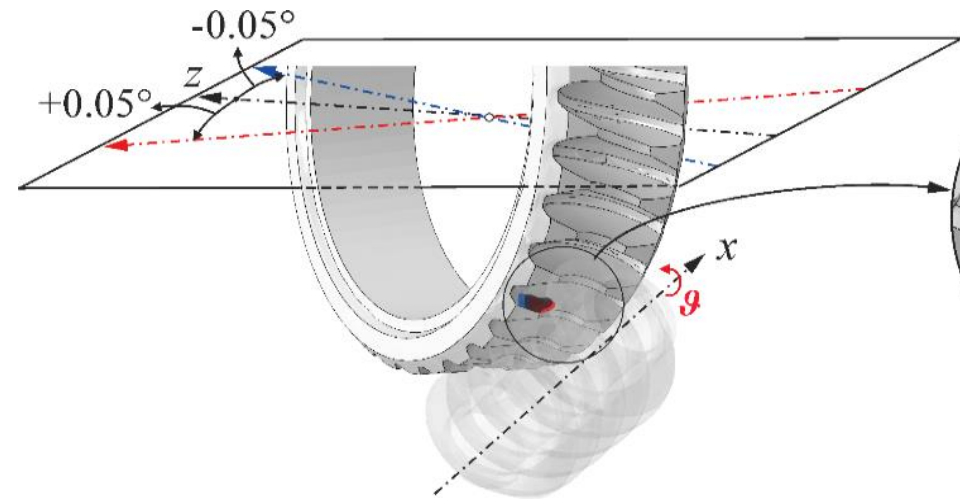

a)

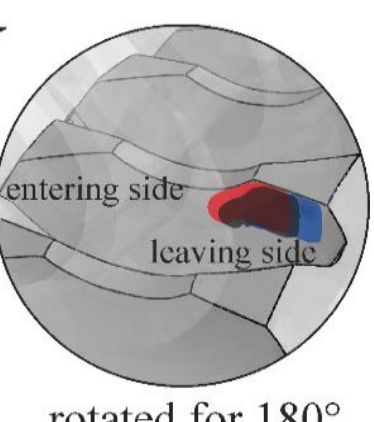

rotated for $180^{\circ}$

b)

Figure 8: a) schematic representation of shaft angle error, b) convention for viewing gear flank.

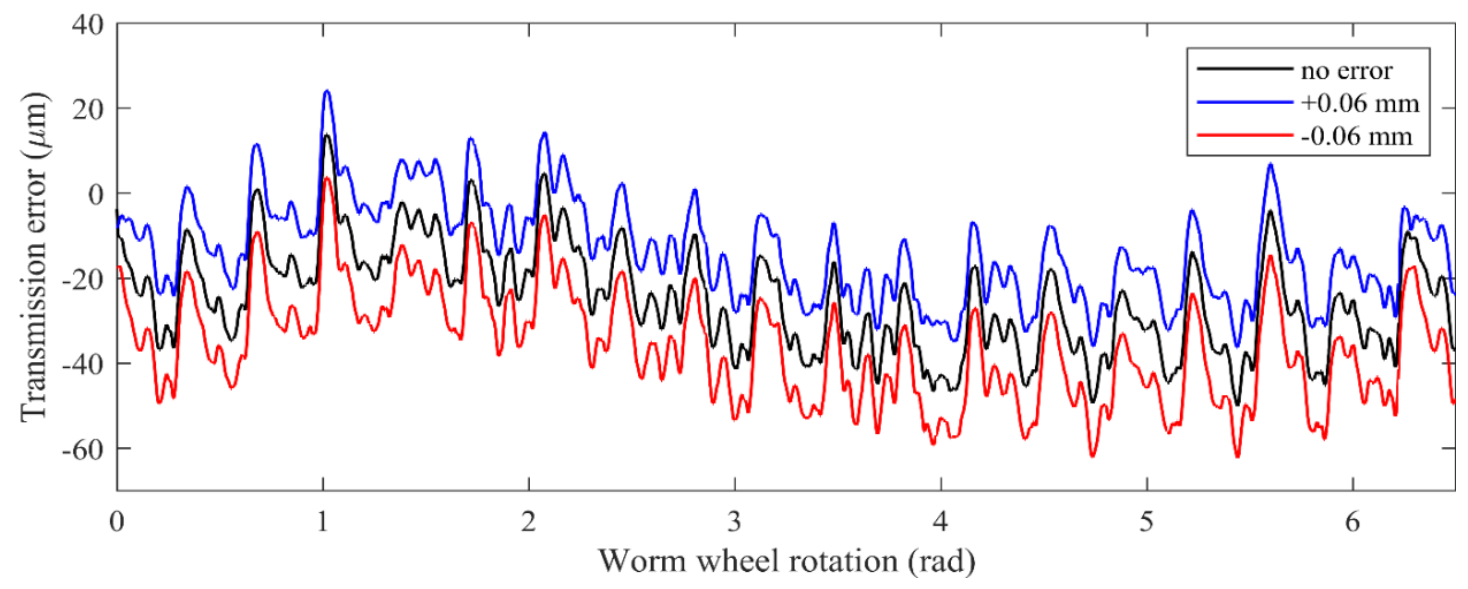

Figure 9: Transmission error with consideration of the centre distance error. 


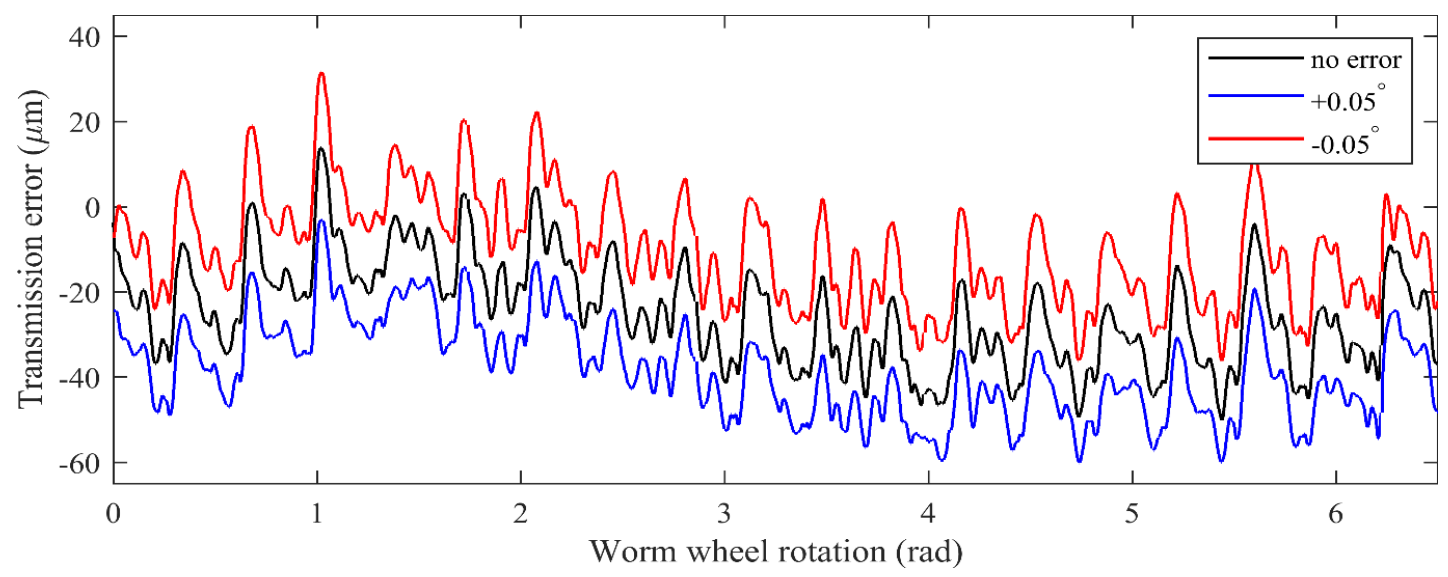

Figure 10: Transmission error with consideration of the shaft angle error.

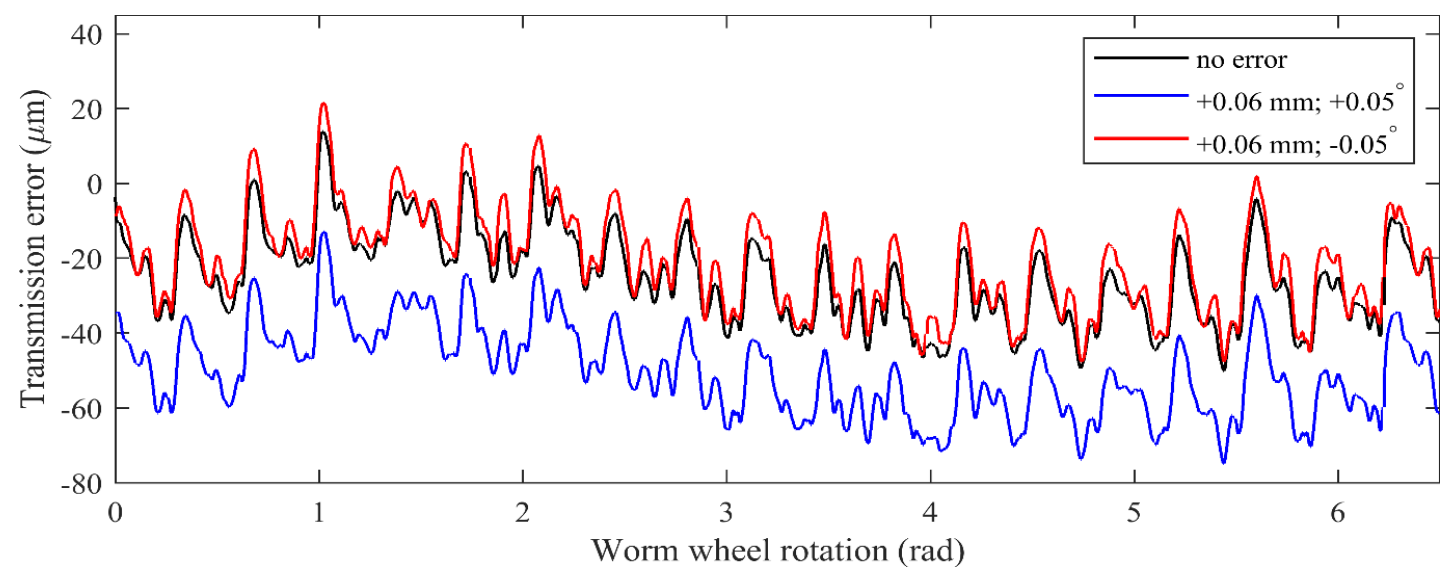

Figure 11: Transmission error with the combined effect of the shaft angle error and centre distance error.

Table IV: Transmission error - results.

\begin{tabular}{|l|c|c|c|c|}
\hline \multicolumn{4}{|c|}{ Referent values (no error): $\boldsymbol{w}_{\mathbf{i}}{ }^{\prime}=\mathbf{3 9 . 1} \boldsymbol{\mu m} ; \boldsymbol{W}_{\mathbf{i}}{ }^{\prime}=\mathbf{6 4 . 8} \boldsymbol{\mu m}$} \\
\hline Assembly error case & $\boldsymbol{w}_{\mathbf{i}}{ }^{\prime}(\mu \mathrm{m})$ & Difference & $\boldsymbol{W}_{\mathbf{i}}{ }^{\prime}(\mu \mathrm{m})$ & Difference \\
\hline Centre distance $(+0.06 \mathrm{~mm})$ & 40.9 & $+4.6 \%$ & 66.9 & $+3.2 \%$ \\
\hline Centre distance $(-0.06 \mathrm{~mm})$ & 38.9 & $-0.5 \%$ & 61.1 & $-5.7 \%$ \\
\hline Shaft angle $\left(+0.05^{\circ}\right)$ & 36.4 & $-6.9 \%$ & 57.8 & $-10.8 \%$ \\
\hline Shaft angle $\left(-0.05^{\circ}\right)$ & 43.3 & $+10.7 \%$ & 68.9 & $+6.3 \%$ \\
\hline Centre distance $(+0.06 \mathrm{~mm})$ and Shaft angle $\left(+0.05^{\circ}\right)$ & 38.8 & $-0.8 \%$ & 62.8 & $-3.1 \%$ \\
\hline Centre distance $(+0.06 \mathrm{~mm})$ and Shaft angle $\left(-0.05^{\circ}\right)$ & 44 & $+12.5 \%$ & 70.3 & $+8.5 \%$ \\
\hline
\end{tabular}

Contact pattern is evaluated on three worm wheel flanks which are chosen based on runout and total cumulative pitch error results (see Figs. 6 and 7). Flank No. 4 (highest negative value of $F_{\mathrm{p}}$ ), flank No. 6 (highest value of $F_{\mathrm{r}}$ ), flank No. 27 (lowest value of $F_{\mathrm{r}}$ ), and their corresponding contact patterns, as well as contact nodal area (CNAREA) values under different assembly error cases, are presented in Table $\mathrm{V}$. The colours represent nodes with respect to their CNAREA values. The highest CNAREA values are represented by the red colour, while the lowest ones (where CNAREA is equal to 0 ) are represented by the blue colour. Summing up all the CNAREA values produces the total CNAREA value given in Table V. All contact patterns are observed on the leaving side of the flank. However, the initial contact area during the running-in phase differs among observed flanks for various assembly error cases. For the "no error" case, the contact area differs up to $40.9 \%$ between observed teeth flanks. The smallest difference of $20.9 \%$ is found for centre distance error of $+0.06 \mathrm{~mm}$ and shaft angle error of $-0.05^{\circ}$. On the other hand, the highest difference in the contact area is equal to $49.7 \%$ for a 
centre distance error of $-0.06 \mathrm{~mm}$. Contact area for tooth flank No. 4 (highest negative value of $\left.F_{\mathrm{p}}\right)$ is the smallest for most assembly error cases. This may be due to the highest accumulated negative pitch error. Both tooth flanks No. 4 and No. 6, which are characterized by a significant amount of negative accumulated pitch error, have considerably smaller initial contact areas when compared to flank No. 27. Based on observed tooth flanks, the initial contact area can be as small as $7.8 \%$ of the total worm wheel tooth flank area, which is approximately $305 \mathrm{~mm}^{2}$ for the given worm wheel geometry. Moreover, it can be observed that negative shaft angle error for the observed worm pair produces a smaller contact area. By comparing contact areas of a single tooth flank between different assembly error cases, it can be noticed that for flank No. 27 the contact area can vary up to $43.4 \%$. More specifically, the contact area ranges from $28 \mathrm{~mm}^{2}$ up to $43.5 \mathrm{~mm}^{2}$. To conclude, depending on assembly errors and worm gear pair deviations, the initial contact area can vary significantly. Thus, the running-in phase of a worm gear pair can have different effects on each tooth flank.

Table V: Contact pattern and contact nodal area.

\begin{tabular}{|c|c|c|c|}
\hline $\begin{array}{c}\text { Assembly error } \\
\text { case }\end{array}$ & $\begin{array}{c}\text { Tooth flank No. } 4 \\
\text { (highest negative } F_{\mathrm{p}} \text { ) }\end{array}$ & $\begin{array}{c}\text { Tooth flank No. } 6 \\
\left.\text { (highest } F_{\mathrm{r}}\right)\end{array}$ & $\begin{array}{l}\text { Tooth flank No. } 27 \\
\quad\left(\text { lowest } F_{\mathrm{r}} \text { ) }\right.\end{array}$ \\
\hline No error & & & \\
\hline $\begin{array}{l}\text { Centre distance } \\
(+0.06 \mathrm{~mm})\end{array}$ & & & \\
\hline $\begin{array}{l}\text { Centre distance } \\
(-0.06 \mathrm{~mm})\end{array}$ & & & \\
\hline Shaft angle $\left(+0.05^{\circ}\right)$ & & & \\
\hline Shaft angle $\left(-0.05^{\circ}\right)$ & & & \\
\hline $\begin{array}{l}\text { Centre distance } \\
(+0.06 \mathrm{~mm}) \text { and } \\
\text { shaft angle }\left(+0.05^{\circ}\right)\end{array}$ & & & CNAR \\
\hline $\begin{array}{l}\text { Centre distance } \\
(+0.06 \mathrm{~mm}) \text { and } \\
\text { shaft angle }\left(-0.05^{\circ}\right)\end{array}$ & & $306 \mathrm{~mm}^{2}$ & \\
\hline
\end{tabular}

Lastly, the limitations of the study should be addressed. Model establishment based on 3D optical scan has several sources of potential inaccuracies. The scan itself has deviations which are provided in Table II. Surface fitting to the underlying mesh creates a surface model whose deviations are presented in Fig. 2. Moreover, establishing the contact by employing the FE model is dependent on worm pair mesh refinement and its ability to accurately capture the geometry of imported parts. Last of all, the FE model with boundary conditions (see Fig. 4) 
does not account for shaft deflections under running-in load. Since one of the main goals of this paper is to compare the effect of geometrical deviations and assembly errors by employing the proposed model, the aforementioned inaccuracies are present in all simulated assembly error cases, thus not affecting relative differences between the presented results.

\section{CONCLUSION}

Dimensional inspection and quasi-static finite element analysis of the worm pair under no-load and running-in load conditions were carried out based on 3D optical scan data of the worm pair and its housing. Presented results suggest that assembly errors do not necessarily result in an increase of the transmission error. Large differences in initial contact areas under running-in conditions are attributed to both manufacturing and assembly errors. The following conclusions are drawn:

- 3D optical scans can be used for dimensional inspection of the worm pairs according to actual standards, thereby reducing the need for special measuring equipment.

- Centre distance and shaft angle errors can result in either an increase or a decrease in the transmission error of the observed worm pair.

- Initial contact area under running-in load conditions can be as small as $7.8 \%$ of the total tooth area, while the difference in the initial contact area among the observed worm wheel teeth varies up to $49.7 \%$.

Due to significant differences in the initial contact area values, an uneven running-in process of the worm wheel teeth is expected. Comparison of the as-manufactured versus run-in worm wheel 3D scans can be utilized to reveal contact pattern development through the running-in phase. Moreover, contact stress distribution before and after the running-in phase could point out areas of increased contact stress values, consequently suggesting potential locations for pitting development. The latter will be the aim of future investigations.

\section{REFERENCES}

[1] Simon, V. (2006). Influence of tooth errors and shaft misalignments on loaded tooth contact in cylindrical worm gears, Mechanism and Machine Theory, Vol. 41, No. 6, 707-724, doi:10.1016/j.mechmachtheory.2005.09.004

[2] Falah, A. H.; Alfares, M. A.; Elkholy, A. H. (2013). Localised tooth contact analysis of single envelope worm gears with assembly errors, The International Journal of Advanced Manufacturing Technology, Vol. 68, No. 9-12, 2057-2070, doi:10.1007/s00170-013-4821-4

[3] Simon, V. (2007). The influence of gear hobbing on worm gear characteristics, Journal of Manufacturing Science and Engineering, Vol. 129, No. 5, 919-925, doi:10.1115/1.2752524

[4] Sohn, J.; Park, N. (2016). Geometric interference in cylindrical worm gear drives using oversized hob to cut worm gears, Mechanism and Machine Theory, Vol. 100, 83-103, doi:10.1016/j.mechmachtheory.2016.02.002

[5] Goch, G. (2003). Gear metrology, CIRP Annals, Vol. 52, No. 2, 659-695, doi:10.1016/S00078506(07)60209-1

[6] Pueo, M.; Santolaria, J.; Acero, R.; Gracia, A. (2017). A review of tangential composite and radial composite gear inspection, Precision Engineering, Vol. 50, 522-537, doi: 10.1016/ j.precisioneng.2017.05.007

[7] Munro, R. G. (1969). Effect of geometrical errors on the transmission of motion between gears, Proceedings of the Institution of Mechanical Engineers, Conference Proceedings, Vol. 184, No. 15, 79-84, doi:10.1243/PIME_CONF_1969_184_445_02

[8] Smith, R. E. (2004). Single-flank testing of gears, Gear Technology, Vol. 21, No. 3, 18-21

[9] Sánchez, M. B.; Pleguezuelos, M.; Pedrero, J. I. (2019). Influence of profile modifications on meshing stiffness, load sharing, and transmission error of involute spur gears, Mechanism and Machine Theory, Vol. 139, 506-525, doi:10.1016/j.mechmachtheory.2019.05.014 
[10] Opalić, M.; Žeželj, D.; Vučković, K. (2015). A new method for description of the pitting process on worm wheels propagation, Wear, Vol. 332-333, 1145-1150, doi:10.1016/j.wear.2015.01.053

[11] DIN 3974-1 (1995). Accuracy of Worms and Worm Gears - Part 1: General Bases, Deutsches Institut für Normung, Berlin

[12] DIN 3974-2 (1995). Accuracy of Worms and Worm Gears - Part 2: Tolerances for Individual Errors, Deutsches Institut für Normung, Berlin

[13] Müller, A. M.; Schubert, D.; Drummer, D.; Hausotte, T. (2020). Determination of the single point uncertainty of customized polymer gear wheels using structured-light scanning with various polygonization settings, Journal of Sensors and Sensor Systems, Vol. 9, No. 1, 51-60, doi: $10.5194 /$ jsss-9-51-2020

[14] Chen, Y.-C.; Chen, J.-Y. (2019). Optical inspection system for gear tooth surfaces using a projection Moiré method, Sensors, Vol. 19, No. 6, Paper 1450, 16 pages, doi:10.3390/s19061450

[15] VDI/VDE 2634-2 (2012). Optical 3D Measuring Systems: Optical Systems Based on Area Scanning, Verein Deutscher Ingenieure, Düsseldorf

[16] Urbas, U.; Zorko, D.; Černe, B.; Tavčar, J.; Vukašinović, N. (2021). A method for enhanced polymer spur gear inspection based on 3D optical metrology, Measurement, Vol. 169, Paper 108584, 14 pages, doi:10.1016/j.measurement.2020.108584

[17] Ghandali, P.; Khameneifar, F.; Mayer, J. R. R. (2019). A pseudo-3D ball lattice artifact and method for evaluating the metrological performance of structured-light 3D scanners, Optics and Lasers in Engineering, Vol. 121, 87-95, doi:10.1016/j.optlaseng.2019.03.005

[18] Vagovský, J.; Buranský, I.: Görög, A. (2015). Evaluation of measuring capability of the optical 3D scanner, Procedia Engineering, Vol. 100, 1198-1206, doi:10.1016/j.proeng.2015.01.484

[19] Simon, V. (2005). Computer aided loaded tooth contact analysis in cylindrical worm gears, Journal of Mechanical Design, Vol. 127, No. 5, 973-981, doi:10.1115/1.1904050

[20] Fang, H.-S.; Tsay, C.-B. (2000). Mathematical model and bearing contacts of the ZN-type worm gear set cut by oversize hob cutters, Mechanism and Machine Theory, Vol. 35, No. 12, 1689-1708, doi:10.1016/S0094-114X(00)00024-0

[21] Macyszyn, L.; Jedryczka, C.; Staniek, R. (2019). Design and finite element analysis of novel twostage magnetic precession gear, International Journal of Simulation Modelling, Vol. 18, No. 4, 586-595, doi:10.2507/IJSIMM18(4)487

[22] Tang, Z. P.; Chen, Z. X.; Sun, J. P.; Hu, Y. T.; Zhao, M. (2019). Noise prediction of traction gear in high-speed electric multiple unit, International Journal of Simulation Modelling, Vol. 18, No. 4, 720-731, doi:10.2507/IJSIMM18(4)CO20

[23] Litvin, F. L.; Gonzalez-Perez, I.; Yukishima, K.; Fuentes, A.; Hayasaka, K. (2007). Design, simulation of meshing, and contact stresses for an improved worm gear drive, Mechanism and Machine Theory, Vol. 42, No. 8, 940-959, doi:10.1016/j.mechmachtheory.2006.08.005

[24] Sohn, J.; Park, N. (2017). Modified worm gear hobbing for symmetric longitudinal crowning in high lead cylindrical worm gear drives, Mechanism and Machine Theory, Vol. 117, 133-147, doi:10.1016/j.mechmachtheory.2017.07.004

[25] GOM. ATOS Professional - 3D Scanning and Inspection Software, from https://www.gom.com/ nl/3d-software/gom-system-software/atos-professional.html, accessed on 20-04-2021

[26] GOM. GOM Inspect - Ecaluation Software for 3D Measurement Data, from https://www.gominspect.com/, accessed on 20-04-2021

[27] VDI/VDE 2608 (2001). Tangential Composite and Radial Composite Inspection of Cylindrical Gears, Bevel Gears, Worms and Worm Wheels, Verein Deutscher Ingenieure, Düsseldorf

[28] Artec3D. Geomagic Design X, from https://www.artec3d.com/3d-software/geomagic-design-x, accessed on 27-04-2021

[29] Abaqus Inc. (2013). Abaqus 6.13: Abaqus/CAE User's Guide, Dassault Systemes, VélizyVillacoublay

[30] Magyar, B.; Sauer, B. (2014). Calculation of the efficiency of worm gear drives, Proceedings of the 2014 International Gear Conference, 15-23, doi:10.1533/9781782421955.15

[31] KISSsoft AG. KISSsoft, from https://www.kisssoft.com/en, accessed on 09-04-2021

[32] Janninck, W. L. (1988). Contact surface topology of worm gear teeth, Gear Technology, Vol. 5, No. 2, 31-47 